\title{
Çok Düşük Doğum Ağırlıklı Pretermlerde Bronkopulmoner Displazi Sıklığı, Risk Faktörleri ve Kısa Dönem Prognozları
}

\author{
The Incidence, Risk Factors and Short Term Prognosis of \\ Bronchopulmonary Dysplasia in Very Low Birth Weight Preterms
}

\author{
Evin ILTER BAHADUR ${ }^{1}$, Esra ÖZER ${ }^{2}$
}

${ }^{1}$ Hacettepe Üniversitesi Tıp Fakültesi, Çocuk Sağlığı ve Hastalıkları, Gelișimsel Pediatri Bilim Dalı, Ankara

${ }^{2}$ Tınaztepe Universitesi Tıp Fakültesi Cocuk Sağlığı ve Hastalıkları Anabilim Dalı, Izmir

\section{Öz}

Bronkopulmoner displazi (BPD) erken doğumla ilişkili en yaygın morbiditelerden biridir. Bu çalışmada BPD risk faktörleri ve BPD tanılı çok düşük doğum ağırlıklı prematüre bebeklerin kısa dönem prognozlarının değerlendirilmesi amaçlandı. BPD tanısı alan çok düşük doğum ağırlıklı prematüre bebekler çalışma grubu olarak $(\mathrm{n}=50), \mathrm{BPD}$ tanısı olmayan çok düşük doğum ağırlıklı prematüre bebekler kontrol grubu $(\mathrm{n}=184)$ olarak çalışmaya dahil edildi. Gestasyonel yaş, doğum ağırlığı, doğum şsekli, prematüre retinopatisi (ROP), patent duktus arteriozus (PDA), sepsis, mekanik ventilasyon süresi, kraniyal ultrasonografi, prenatal öykü hastane kayıtlarından kaydedildi. BPD tanılı prematüre bebeklerin nörogelişimsel durumu Denver-II gelişimsel tarama testi ile değerlendirildi. Çalışmada gebelik yaşına göre düşük doğum ağırlıklı olma (SGA), ROP, PDA ve sepsis tanılarının yüzdeleri, surfaktan tedavi oranı ve doğum ağırlığı açısından çalışma ve kontrol grupları arasında istatistiksel olarak anlamlı farklılıklar saptandı. Çalışma grubu oksijen ihtiyacına göre üç gruba (hafif, orta, şiddetli BPD) sinıflandırıldı. Üç grup arasında gebelik yaşı, doğum kilosu ve mortalite açısından istatistiksel olarak anlamlı fark saptandı. Şiddetli BPD grubunda gebelik yaşı ve doğum ağırlığının ortalama değerleri en düşük, mortalite oranı da en yüksek bulundu. Çalışma grubunun \%21.7'sinde Denver-II gelişimsel tarama testine göre nörogelişimsel gecikme saptand. Düşük doğum ağırlığı ve düşük gebelik yaşı BPD için risk faktörü ve mortaliteyle ilişkili bulunurken, aynı zamanda BPD tanısının nörogelişimsel gecikme, sepsis, PDA ve ROP tanılarıyla da iliş̧ili olduğu saptanmıştır.

Anahtar Kelimeler: Bronkopulmoner Displazi, Cok Düşük Doğum Ağırlıklı Prematüre, Nörogelişimsel Gecikme, Risk Faktörleri

\section{Giriș}

Neonatoloji alanındaki tüm gelişmelere rağmen bronkopulmoner displazi (BPD) preterm doğumun en sık görülen komplikasyonlarından biri olmaya devam etmektedir. Giderek daha küçük bebeklerin yaşatılmaya başlamasına rağmen BPD sıklığında belirgin azalma olmamıştır (1). Bronkopulmoner displazi ilk kez 1967 yllinda Northway ve arkadaşları tarafından şiddetli respiratuvar distres sendromu (RDS) olup mekanik ventilasyon tedavisi

\section{Evin İLTER BAHADUR} Esra ÖZER

\section{ORCID No}

0000-0003-0592-6710

0000-0003-2634-7136

Başvuru Tarihi / Received:

12.06.2020

Kabul Tarihi / Accepted

01.02 .2021

Adres / Correspondence

Evin İLTER BAHADUR

Hacettepe Üniversitesi Tip Fakültesi, Çocuk Sağlığı ve Hastalıkları, Gelişimsel Pediatri Bilim Dalı, Ankara e-posta / e-mail evinbahadur@gmail.com

\begin{abstract}
Bronchopulmonary dysplasia (BPD) is one of the most common morbidities associated with preterm birth. This study aims to investigate the risk factors of BPD and short-term prognosis of very low birth weight (VLBW) preterm infants with BPD. VLBW preterm infants, who were diagnosed with BPD, were included in the study as a case group $(n=50)$, VLBW preterm infants without BPD were included as the control group $(n=184)$. Gestational age, birth weight, diagnosis of retinopathy of prematurity (ROP), patent ductus arteriosus (PDA), sepsis, the duration of mechanical ventilation, cranial ultrasonography, history of antenatal period recorded from the hospital records. The developmental status of preterm infants with BPD was assessed by Denver Developmental Screening Test II (DDST-II). There were statistically significant differences in terms of birth weight and small for gestational age, ROP, PDA, sepsis, surfactant therapy rates between the case and the control groups. The case group was classified into three groups (mild, moderate, severe) according to the oxygen requirement. There was a statistically significant difference between the three groups in terms of gestational age, birth weight and mortality. The means of gestational age and birth weight were the lowest, mortality was the highest in the severe BPD group. In the case group, $21.7 \%$ of preterm infants had neurodevelopmental delay according to the DDST-II. It is found that low birth weight and gestational age are risk factors for BPD and associated with mortality. It is also found that BPD associated with neurodevelopmental delay, sepsis, PDA and ROP.
\end{abstract}

Keywords: Bronchopulmonary Dysplasia, Very Low Birth Weight Preterms, Neurodevelopmental Delay, Risk Factors almış bebeklerde postnatal 28.günde oksijen tedavisine ihtiyaç gösteren kronik akciğer hastalığ olarak tanımlanmış ve "bronkopulmoner displazi" terimi kullanılmıştır (2). Daha sonra Northway'in tanımlamasındaki ventilasyon kriterleri 28.günde oksijen gereksinimi ve anormal akciğer grafi bulgularını kullanarak değiştirilmiş, hatta postkonsepsiyonel 36. haftada oksijen gereksiniminin varlığ 1 daha doğru bir kriter olarak öne sürülmüştür (3).

Bronkopulmoner displazinin etyopatogenezi henüz tam olarak aydınlatılamamıştır ancak multifaktöriyel olduğu düşünülmektedir (4). Genetik faktörlerin yanı sıra uzun süreli oksijene maruz kalma, enfeksiyonlar, mekanik ventilasyona bağlı barotravma ve volutravma etiyolojide rol oynamaktadır (1-6). Yenidoğan bakımı geliştikçe preterm bebeklerin kronik pulmoner sekel, sağkalım ve yaşam kalitesi değişmektedir. Yapılan çalışmalarda BPD'li preterm bebeklerin yaşamın ilk 2 yılında daha fazla hastaneye yattıkları ve öğrenme, 
konuşma ve davranış bozukluklarının daha fazla olduğu belirtilmektedir (6).

Bu çalışmada yenidoğan yoğun bakım ünitesinde izlenen çok düşük doğum ağırlıklı preterm bebeklerde BPD gelişimi üzerine etkili risk faktörlerinin ve kısa dönem prognozlarının araştırılması amaçlanmıştır.

\section{Gereç ve Yöntem}

Retrospektif olarak düzenlenen bu çalışmada, Mayıs 2007-Haziran 2010 tarihleri arasında BPD tanısı alan çok düşük doğum ağırlıklı (doğum ağırlığı 1500 gramın altında) ve gebelik yaşı 32 haftadan daha küçük olgular çalışma grubunu oluşturmuştur. Patent duktus arteriyozus (PDA) dışında konjenital kalp hastalığı saptanan olgular, major konjenital anomalisi olan bebekler ve metabolik hastalık saptanan yenidoğanlar çalışma kapsamı dışında bırakılmıştır. Kontrol grubunu; aynı dönemde klinikte izlenen, gebelik yaşı 32 haftadan küçük ve doğum ağırlığı 1500 gramın altında olan; major konjenital anomalisi ve metabolik hastalığ olmayan, kronik akciğer hastalığı tanısı almamış bebekler oluşturmuştur. Çalışmaya ait etik kurul onayı TC Sağlık Bakanlığı İzmir Tepecik Eğitim ve Araştırma Hastanesi Girişimsel Olmayan Araştırmalar Etik Kurulu'ndan alındı (08.06.2020/ Karar no: 2020/6-2).

Hastaların hastaneye yatış ve izlem dosyalarından antenatal ve perinatal döneme ait öyküleri, gebelik yaşı, doğum ağırlığı, cinsiyeti, doğum şekli, çoğul gebelik durumu, yenidoğan ünitesinde yatı̧̧ süresi kaydedildi. Hastaların dosyalarından antenatal risk faktörleri olarak erken membran rüptürü (EMR) varlığı, gebelik yaşına göre doğum ağırlığının 10. persentil altında olması (SGA) kaydedildi. Ayrica hastaların RDS tanısı alma durumu, PDA varlığı, mekanik ventilatör gereksinimi ve süresi, sepsis geçirme durumu kaydedildi. Çalışmada yer alan bebeklere BPD tanısı ve sınıflaması Türk Neonatoloji Derneği BPD korunma ve izlem rehberindeki tanımlama kriterlerine göre konuldu (7). Hasta kayıtlarından prematüre retinopatisi (ROP) muayene sonuçları, kraniyal ultrasonografi raporları ve mortalite durumları kaydedildi. Taburcu edilen olgulardan poliklinikte izlenen vakaların poliklinik izlem dosyalarından düzeltilmiş yaş 18 . aydaki Denver II Gelişim Tarama Testleri (DGTT) sonuçları değerlendirildi. DGTT'de olguların kaba ve ince motor, dil gelişimi ve sosyal gelişim bakımından dört başlık altında nöromotor gelişimleri değerlendirildi. Anormal DGTT testi olan olgulara üç ay sonra test tekrarı uygulandı. İkinci testte de aynı performansı gösteren olgular "Anormal DGTT" diğer olgular "Normal DGTT" grubu olarak kabul edildiler.

İstatiksel analizler SPSS 20.0 programında bağımsız örnekler t-testi, Mann Whitney U testi, Kruskal-Wallis ve ki- kare testi kullanılarak yapıldı.
Post-Hoc analizlerde Bonferroni düzeltmesi kullanıldı. P değerinin 0.05 'den küçük olması istatiksel olarak anlamlı kabul edildi.

\section{Bulgular}

Mayıs 2007-Haziran 2010 tarihleri arasında BPD tanısı ile izlenen 50 olgu çalışma grubunu oluşturdu. Çalışma grubundaki olguların ortalama doğum ağırlıkları $1188 \pm 371$ gram, boy $36.5 \pm 4.1 \mathrm{~cm}$, baş çevresi $26.1 \pm 3.5 \mathrm{~cm}$, doğum haftaları $27.9 \pm 2.5$ hafta olarak hesaplandı. Olguların 31'i (\%62) erkek, 19'u (\%38) kız bebeklerdi. Hastaların 24'ü (\%48) normal spontan doğumla doğmuştu, 8'inde (\%16) SGA mevcuttu. Çalışma grubundakilerin \%34'üne $(n=17)$ antenatal steroid uygulandığ olguda (\%30) 72 saatten daha uzun süreli, 5 olguda (\%10) ise 24-72 saatlik EMR olduğu, 40 olguya $(\% 80)$ surfaktan tedavisi uygulandiğ 1,25 olgunun (\%50) PDA, 34 olgunun (\%68) sepsis tanısı aldığ 1 saptand. Çalışma grubunun mekanik ventilasyon süresi ortalama $24.4 \pm 26$ gün, yaşayan olguların $(\mathrm{n}=40)$ ortalama $17.6 \pm 16.5$ gün kaybedilen olguların $52 \pm 38$ gün olarak hesapland $1 \quad(p=0.001)$. Klinik sinıflandirmada 16 olgu (\%32) hafif, 16 olgu (\%32) orta ve 18 olgu (\%36) ağır BPD olarak değerlendirildi. Çalışma grubunda mortalite oranı $\% 20$ olarak bulundu. ROP taramasinda 29 olguda (\%58) ROP bulgusu saptandi. ROP saptanan 29 olgudan 22 olguya lazer tedavisi uyguland, 7 olgu tedavisiz izlendi. Yaşayan olgulardan 23 olguya düzeltilmiş 18.ayda DGTT uygulandı ve 5 olguda (\%21.7) DGTT anormal olarak saptand.

Çalışmada klinik ağırlığa göre gruplandırılan hastaların karşılaştırılması Tablo 1'de gösterilmiştir. Gruplar arasında gebelik yaşı ve doğum ağırlığı açısından anlamlı istatistiksel farklılık bulunurken, boy, baş çevresi, cinsiyet, doğum şekli ve SGA bakımından anlamlı istatistiksel farklılık saptanmadi. Antenatal steroid uygulanma, EMR, sepsis, PDA ve ROP sıklığında da gruplar arasında anlamlı istatistiksel fark bulunmadı. Ağır BPD'li grupta mortalite anlamlı olarak daha yüksekti. İkili grupların karşılaştırılmasında istatiksel olarak anlamlı farklılıklar Tablo 1'de gösterilmiştir.

Kontrol grubundaki olguların $(n=184)$ ortalama doğum ağırlıkları 1069 \pm 269 , ortalama gebelik yaşları $28 \pm 2.1$ hafta olarak saptand. Kontrol grubunun 105'i (\%58) erkek, 79'u (\%42) k1z bebeklerdi. Kontrol grubundaki çok düşük doğum ağırlıklı 184 bebeğin doğum ağırlığı, BPD grubuna göre istatistiksel olarak anlamlı oranda daha düşüktü $(\mathrm{p}=0.01)$. Gruplar arasında gebelik yaşı, cinsiyet, doğum şekli, EMR, antenatal steroid uygulanma açısından anlamlı farklılık bulunmadı (Tablo 2). Kontrol grubunda SGA olan bebek sayıs BPD grubuna göre daha yüksek iken $(p=<0.001)$; surfaktan kullanımı $(\mathrm{p}=<0.001)$, sepsis $(\mathrm{p}=<0.001)$, PDA $(p=0.01)$ ve ROP $(p=<0.001)$ siklığı da BPD grubunda kontrol grubuna göre istatistiksel açıdan anlamlı düzeyde yüksek saptandı. 
Tablo 1. Bronkopulmoner Displazi tanılı olguların klinik evrelere göre değerlendirilmesi

Gebelik yaşı (hafta)*

Doğum ağırlığı (gram)*

Boy $(\mathrm{cm})^{*}$

Baş çevresi $(\mathrm{cm})^{*}$

$\mathrm{SGA}^{+} \mathrm{N}(\%)$

Cinsiyet (K1z/Erkek)

Doğum şekli (Normal/Sezaryen)

Antenatal steroid N (\%)

Erken membran rüptürü N (\%)

Sepsis N (\%)

Patent duktus arteriozus N (\%)

Prematüre retinopatisi N (\%)

Yatıs süresi (gün)*

Mortalite N (\%)

BPD: Bronkopulmoner Displazi. + SGA: Gebelik yașına göre düșük doğum ağırlığ

\begin{tabular}{cccc} 
Hafif BPD $(\mathbf{n = 1 6})$ & Orta BPD $(\mathbf{n = 1 6})$ & A ğır BPD $(\mathbf{n}=\mathbf{1 8})$ & $\mathbf{p}$ \\
\hline $28.0 \pm 2.1^{\mathrm{a}}$ & $29.1 \pm 2.4^{\mathrm{b}}$ & $26.7 \pm 2.4^{\mathrm{ab}}$ & 0.02 \\
$1250 \pm 323^{\mathrm{c}}$ & $1327 \pm 374$ & $1008 \pm 355^{\mathrm{c}}$ & 0.03 \\
$36.9 \pm 4.1$ & $37.8 \pm 3.5$ & $35.2 \pm 4.4$ & 0.24 \\
$27.0 \pm 4.7$ & $26.8 \pm 2.3$ & $24.8 \pm 2.9$ & 0.12 \\
$1(6.2)$ & $4(25)$ & $3(16.6)$ & 0.35 \\
$6 / 10$ & $6 / 10$ & $7 / 11$ & 0.99 \\
$7 / 9$ & $5 / 11$ & $12 / 6$ & 0.10 \\
$7(43.7)$ & $6(37.5)$ & $4(22.2)$ & 0.39 \\
$6(37.5)$ & $8(50)$ & $6(37.5)$ & 0.18 \\
$12(75)$ & $9(56.2)$ & $13(72.2)$ & 0.46 \\
$7(43.7)$ & $6(37.5)$ & $12(66.6)$ & 0.19 \\
$9(56.2)$ & $8(50)$ & $12(66.6)$ & 0.37 \\
$67.9 \pm 15.8$ & $75.1 \pm 28.1$ & $144.5 \pm 26.7$ & 0.30 \\
$2(12.5)^{\mathrm{d}}$ & $1(6.2)$ & $7(38.8)^{\mathrm{d}}$ & 0.03 \\
\hline
\end{tabular}

Tablo 2. Bronkopulmoner Displazi tanılı olguların kontrol grubu preterm bebekler ile karşılaştırılması

\begin{tabular}{llll}
\hline & BPD (Çalışma Grubu) (n=50) & Kontrol Grubu (n=184) & p \\
\cline { 2 - 4 } Gebelik yaşı (hafta)* & $27.9 \pm 2.5$ & $28 \pm 2.1$ & 0.72 \\
Doğum ağırlığı (gram)* $_{\text {SGA }^{+} \text {N (\%) }}^{1188 \pm 371}$ & $1069 \pm 269$ & 0.01 \\
Cinsiyet (Kız/Erkek) & $8(16)$ & $37(20)$ & $<0.001$ \\
Doğum şekli (Normal/Sezaryen) & $19 / 31$ & $79 / 105$ & 0.53 \\
Erken membran rüptürü N (\%) & $24 / 26$ & $113 / 71$ & 0.08 \\
Antenatal steroid N (\%) & $17(40)$ & $53(29)$ & 0.13 \\
Surfaktan gereksinimi N (\%) & $40(80)$ & $62(34)$ & 0.96 \\
Patent duktus arteriyozus N (\%) & $25(50)$ & $70(38)$ & $<0.001$ \\
Sepsis N (\%) & $34(68)$ & $59(32)$ & 0.01 \\
Prematüre retinopatisi N (\%) & $29(58)$ & $49(27)$ & $<0.001$ \\
\hline
\end{tabular}

* Değerler ortalama + standart sapma cinsinden verilmiştir.

BPD: Bronkopulmoner Displazi. + SGA: Gebelik yaşına göre düşük doğum ăğırlı̆g

\section{Tartışma}

Yenidoğan yoğun bakımında hızla artan gelişmeyle birlikte, günümüzde daha fazla sayıda ve daha küçük preterm bebek yaşatılmaktadır. Yoğun bakım teknolojisinin gelişmesi, surfaktan kullanımının yaygınlaşması ile sağkalımı artan preterm bebeklerin uzun dönem prognozunda en önemli morbiditelerden birisi de BPD'dir. Ünitemizde Mayıs 2007- Haziran 2010 arasında yatan doğum ağırlığ1 1500 gramın altında olan prematürelerin \%5.9'unda BPD saptanmış olup, düşük doğum ağırlığı ve düşük doğum haftası BPD tanıs1 için birer risk faktörü olarak bulunmuştur. BPD'li olguların kısa dönem prognozlarına bakıldığında \%21.7' sinde DGTT'ne göre nörogelişimsel gecikme olduğu ve lazer tedavisi gerektiren ROP tanısında artış olduğu tespit edilmiștir.

Yaşatılan bebeklerde BPD sıklığı farklı çalışma gruplarında değerlendirilmiş ve \%11-50 olarak bildirilmiştir (8-11). Özkan ve arkadaşları birimlerinin BPD sıklığını \%30 olarak bildirirken bu olguların \%36'sının 28. gebelik haftasının altında olduğunu, \%41.9'unun da doğum ağırlığının 1000 gr altında bulunduğunu belirtmişlerdir (12). Aldemir ve arkadaşlarının yaptığ \%6.3 olarak bildirilmiştir (13). Yenidoğan Yoğun Bakım Birimimizde Mayıs 2007- Haziran 2010 arasında yatan doğum ağırlığı 1500 gramın altında
837 bebekten 50'sinde BPD geliştiği saptanmıştır ve BPD sıklığı ünitemiz için çalışmanın yapıldı ̆̆ tarihler arasında \%5.9 olarak hesaplanmıştır.

Respiratuvar distres sendromu ve sepsis gibi önemli neonatal sorunlar erkek bebeklerde daha s1k görülmektedir ve mortalitesi de erkek bebeklerde daha yüksektir (14). Erkek hastalar aleyhine olan bu durumun nedeni tam olarak aydınlatılamamıştır, ancak genel olarak gonadotropinlerin etkisi nedeni ile olduğu görüşü kabul edilmektedir (15). Literatürde de BPD'nin beyaz 1rk ve erkek cinsiyette daha sık olduğu belirtilmiştir $(13,16)$. Çalışmamızda literatür ile uyumlu olarak BPD'li bebeklerin \%62'si erkek idi. $\mathrm{Bu}$ durumun respiratuvar distres sendromunun erkek bebeklerde daha sık ve daha ağır seyretmesi ile ilişkili olmasından kaynaklandığını düşünmekteyiz.

Antenatal steroidlerin doğumdan 24-48 saat önce anneye uygulanmasının RDS'nin sıklığını ve şiddetini azalttığı gösterilmiştir (17). Kortikosteroidlerin 34 gebelik haftasının altındaki gebelere verilmesi uygundur. Doğumdan 24 saatten daha kısa süre önce verilmesi bile neonatal mortalite, respiratuvar distres sendromu ve intraventriküler kanama sıklığında önemli azalmalara yol açmaktadır (18). $\mathrm{Bu}$ önemli yararlarına rağmen antenatal kortikosteroidin, olgularımızın sadece \%34'üne uygulanmış olduğu saptandı. Çalışmamızda antenatal steroidin mortalite ve BPD şiddeti üzerine etkisi izlenmedi. 
Bronkopulmoner displazi etiyopatogenezinde enfeksiyon ve enflamasyon önemli risk faktörlerindendir. Özellikle annede koriyoamniyonit varlığının fetal kord kanlarında ve amniyon sıvısında sitokinlerin artışına yol açarak BPD gelişimini kolaylaştırdığı saptanmıştır (19). BPD gelişen bebeklerin kord kanında ve amniyon sivisinda interlökin-6 başta olmak üzere çeşitli inflamatuar sitokinlerin yüksek seviyelerde olduğu gösterilmiştir (20). Yine BPD gelişen bebeklerin kord kanında IgM seviyelerinin yüksek olması da perinatal kazanılan enfeksiyonların BPD gelişimindeki rolünü desteklemektedir. Özkan ve arkadaşlarının yaptığı çalışmada annede koryoamniyonit öyküsü olan bebeklerde yaklaşık 2.5 kat daha fazla BPD geliştiği saptandığı; koriyoamniyonit olmaksızın EMR olan annelerin bebeklerinde de EMR olmayanlara göre BPD'nin daha yüksek oranlarda görüldüğü ancak bu farklılığı istatiksel olarak anlamlı olmadığ belirtilmektedir (12). Çalışmamızda hasta grubumuzun tamamının hastane dışından sevkli olmasi nedeni ile klinik koryoamniyonit konusunda yeterli bilgi alınamamıştır. Ancak olguların \%40'1nda EMR öyküsü bulunmakta idi. Aldemir ve arkadaşlarının yaptığı çalışmada EMR sıklığı \%24 olarak belirtilmiştir (13). Çalışma grubumuzdaki olgularda EMR sıklığının mortalite ve BPD'nin ağırlığı ile ilişkili olmadığı görülmektedir.

İntrauterin enfeksiyonlar gibi postnatal enfeksiyonlar da BPD gelişimini kolaylaştırmaktadır. Literatürde geç sepsis ile BPD gelişimi arasında ilişki olduğu bulunmuştur (21). Çalışmamızda BPD'li olguların \%68'inde sepsis geçirme öyküsü mevcuttu. Çalışmamızda yer alan olguların sepsis olarak değerlendirilmesinde kültür pozitif vakalar dışında klinik olarak sepsis düşündüren ve antibiyotik verilen tüm vakaların sepsis olarak değerlendirilmesi nedeni ile sepsis oranının yüksek bulunduğunu düşünmekteyiz.

Patent duktus arteriyozus, sol-sağ şant nedeniyle pulmoner kan akımında artmaya ve akciğer ödemine neden olur. Akciğer sıvısındaki artış akciğer fonksiyonunu ve gaz alışverişini olumsuz yönde etkileyerek BPD gelişimini kolaylaştırır. Aynı zamanda pulmoner kan akımının artması enflamatuvar cevabı da tetikleyerek de BPD riskini artırmaktadır (22). Çalışmamızda BPD gelişen olguların yarısında PDA saptandığı, ancak PDA'nın BPD olgularında mortaliteyi etkilemediği görülmektedir. BPD tanısı almış, çok düşük doğum ağırlıklı 244 preterm bebeğin değerlendirildiği retrospektif bir çalışmada da çalışmamızla benzer şekilde PDA oranının \%51 olduğu bildirilmiştir (23).

Surfaktan kullanımı ile mortalitenin azalması ile birlikte daha fazla çok düşük doğum ağırlıklı preterm bebek yaşatılmakta, ancak "yeni BPD" sıklığı azalmamaktadır (24). Çalışmamızda yer alan çok düşük doğum ağırlıklı ve BPD tanısı almış 50 olgunun \%80'ine surfaktan verildiği ve BPD olmayan preterm bebeklere göre surfaktan gereksiniminin daha fazla olduğu görülmüştür. $\mathrm{Bu}$ durumun daha ağır RDS'li olgularda BPD gelişiminin daha fazla olmasından kaynaklandığ kanısindayız.

BPD patogenezinde mekanik ventilasyon, barotravmaya yol açması ve inflamasyona katkıda bulunması nedeniyle yer almaktadır. Bu nedenle mekanik ventilasyon tedavisi uzadıkça BPD riski artmaktadır (1,5). Çalışmamızdaki BPD'li olguların ortalama $24.4 \pm 26$ gün mekanik ventilasyon desteği aldığı; kaybedilen olguların daha uzun süre mekanik ventilatörde izlendiği saptanmıştır. Yapılan çalışmalarda RDS'si olan bebeklerin daha fazla mekanik ventilasyon ve oksijen desteğine ihtiyaç duyması ile BPD riskinin de arttığı belirtilmiştir (16). Bizim çalışmamızda da RDS'si olup surfaktan tedavisi uygulanan olgu sayısı fazla olduğundan mekanik ventilatörde izlem diğer çalışmalara göre yüksek saptanmıştır.

Çalışmamızdaki BPD'li olgular klinik sınıflamaya göre gruplandırıldığında \%32'sinin hafif, \%32'sinin orta ve \%36'sının ağır BPD olduğu bulunmuştur. Gruplar arasında gebelik yaşı ve doğum ağırlığı açısından anlamlı istatistiksel farklılık olduğu, gebelik yaşı ve doğum ağırlığ azaldıkça hastalığın şiddetinin arttığı görülmüştür. Ayrıca ağır BPD olan olgularda mortalitenin de anlamlı derecede arttığı saptanmıştır. Bu durumun, günümüzde daha fazla sayıda küçük preterm bebeğin yaşatılıyor olması ile ilişkili olduğu görüşündeyiz.

Preterm bebeklerde BPD dişında görülen diğer önemli sorunlardan birisi de prematüre retinopatisidir. Prematüre retinopatisinin patogenezinde ağır prematürelik yanı sıra uzun süreli oksijen tedavisi almak da sorumlu faktörlerdendir. Yapılan çalışmalarda çok düşük doğum ağırlıklı preterm bebeklerde BPD sıklığı ile ROP sıklığının birlikte arttığı gösterilmiştir (13). Çalışmamızdaki olguların \%58'inde herhangi bir evrede prematüre retinopatisi tespit edildi. Toplam 50 BPD vakasının \%44'ünün lazer ile fotokoagulasyon gerektiren ROP olduğu saptand. BPD olmayan preterm bebeklerde daha az ROP saptanması nedeni ile, çalışma grubundaki olguların solunum problemleri nedeni ile daha uzun süre oksijen tedavisi almalarının ROP sıklığındaki artış ile ilişkili olabileceği görüşündeyiz.

Bronkopulmoner displazi, uzamış ventilasyon, oksijen tedavisi, hipoksi, apne, enfeksiyona eğilim, intraventriküler kanama, steroid kullanımının yan etkileri gibi birçok risk faktörleri nedeniyle nörogelişimsel bozukluk gelişebilen bir gruptur. Bronkopulmoner displazi pretermlerde nörogelişimsel prognozu kötü etkileyen risk faktörlerinden birisidir. Olgularımızın \%21.7'si DGTT ile nörogelişimsel bakımdan anormal olarak değerlendirilmiştir. Çok düşük doğum ağırlıklı preteremlerde BPD'nin gebelik yaşı, doğum ağırlı̆̆ ve cinsiyetten bağımsız olarak nörogelişimsel 
prognozu olumsuz olarak etkilediği gösterilmiştir (25). Ayrıca çalışmamızda hastaların kraniyal ultrasonografik değerlendirilmelerinde $\% 40$ olguda anormal ultrason bulgusu saptanmış olmasının, bu yüksek orandaki anormal nörogelişimsel prognoza katkıda bulunan faktörlerden olduğunu düşünmekteyiz.

Çok merkezli araştırmalarda doğum ağırlığı 1000 gr'dan küçük BPD'li bebeklerde mortalite oranının \%12-38 arasında değiștiği bildirilmektedir $(26,27)$. Çalışmamızdaki BPD olgularında saptadığımız \%20 mortalite oranının literatür ile uyumlu olduğunu düşünmekteyiz.

Sonuç olarak, düşük doğum ağırlıklı, gebelik yaşı küçük preterm bebeklerde, BPD'nin daha ölümcül seyrettiği, BPD gelişiminde düşük doğum ağırlığı ve erken gebelik yaşının etkili faktörler olduğu, BPD olgularında kötü nörogelişimsel sonuçların ve tedavi gerektiren ROP sıklığının arttı̆̆ tespit edilmiştir. Daha ileri araştırmalarla BPD gelişimini önleyici tedavi olanaklarının araștırılmasının yaşatılan çok düşük doğum ağırlıklı preterm bebeklerde yaşam kalitesini yükseltmede önemli olabileceği görüşüne varılmıştır.

Etik Kurul Onayı: T.C. Sağlık Bakanlığı İzmir Tepecik Eğitim ve Araştırma Hastanesi Girişimsel Olmayan Araştırmalar Etik Kurulu'ndan alınmıştır (08.06.2020/ Karar no: 2020/6-2).

\section{Kaynaklar}

1. Jobe AH. Mechanisms of lung injury and bronchopulmonary dysplasia. Am J Perinatol. 2016;33(11):1076-8.

2. Northway Jr WH, Rosan RC, Porter DY. Pulmonary disease following respirator therapy of hyaline-membrane disease: bronchopulmonary dysplasia. $\mathrm{N}$ Engl J Med. 1967;276(7):357-68.

3. Jobe AH, Bancalari E. Bronchopulmonary dysplasia. Am J Respir Crit Care Med. 2001;163(7):1723-9.

4. Abman SH, Bancalari E, Jobe A. The evolution of bronchopulmonary dysplasia after 50 years. Am J Respir Crit Care Med. 2017;195:421-4.

5. Bancalari E, Claure N, Sosenko IR, editors. Bronchopulmonary dysplasia: changes in pathogenesis, epidemiology and definition. Semin Neonatol; 2003: Elsevier.

6. Davidson LM, Berkelhamer SK. Bronchopulmonary dysplasia: chronic lung disease of infancy and long-term pulmonary outcomes. J Clin Med. 2017;6(1):4.

7. Arsan S, Korkmaz A, Oğuz S. Turkish Neonatal Society guideline on prevention and management of bronchopulmonary dysplasia. Türk Pediatri Arsivi. 2018;53(Suppl 1):138.

8. Stoll BJ, Hansen NI, Bell EF, et al. Neonatal outcomes of extremely preterm infants from the NICHD Neonatal Research Network. Pediatrics. 2010;126(3):443-56.

9. Adams M, Bassler D, Bucher HU, et al. Variability of very low birth weight infant outcome and practice in Swiss and US neonatal units. Pediatrics. 2018;141(5). e20173436.
10. Isayama T, Lee SK, Yang J, et al. Revisiting the definition of bronchopulmonary dysplasia: effect of changing panoply of respiratory support for preterm neonates. JAMA Pediatr. 2017;171(3):271-9.

11. Su B-H, Hsieh W-S, Hsu C-H, et al. Neonatal outcomes of extremely preterm infants from Taiwan: comparison with Canada, Japan, and the USA. Pediatr Neonatol. 2015;56(1):46-52.

12. Ozkan H, Koksal N, Cetinkaya M, Canitez Y. Risk factors for bronchopulmonary dysplasia/Bronkopulmoner displazide risk faktorleri. Güncel Pediatri. 2008:66-72.

13. Aldemir EY, Kavuncuoğlu S, Özbek S, Altuncu E, Çizmeci MN. Bronkopulmoner displazi gelișen cok düsük doğum ağırlıklı erken doğmuş bebeklerin değerlendirilmesi. Turk Pediatr Arsivi. 2010;45(1)

14. Brothwood M, Wolke D, Gamsu H, Benson J, Cooper D. Prognosis of the very low birthweight baby in relation to gender. Arch Dis Child. 1986;61(6):559-64.

15. Cho J, Holditch-Davis D. Effects of perinatal testosterone on infant health, mother-infant interactions, and infant development. Biol Res Nurs. 2014;16(2):228-36.

16. Tapia JL, Agost D, Alegria A, et al. Bronchopulmonary dysplasia: incidence, risk factors and resource utilization in a population of South-American very low birth weight infants. J Pediatr. (Rio J.) 2006;82(1):15-20.

17. Smrcek J, Schwartau N, Kohl M, et al. Antenatal corticosteroid therapy in premature infants. Arch Gynecol Obstet. 2005;271(1):26-32.

18. Sweet DG, Carnielli V, Greisen G, et al. European consensus guidelines on the management of respiratory distress syndrome-2019 update. Neonatology. 2019;115(4):432-50.

19. Watterberg KL, Demers LM, Scott SM, Murphy S. Chorioamnionitis and early lung inflammation in infants in whom bronchopulmonary dysplasia develops. Pediatrics. 1996;97(2):210-5.

20. D'Angio CT, Ambalavanan N, Carlo WA, et al. Blood cytokine profiles associated with distinct patterns of bronchopulmonary dysplasia among extremely low birth weight infants. J Pediatr. 2016;174:45-51.

21. Lapcharoensap W, Kan P, Powers RJ, et al. The relationship of nosocomial infection reduction to changes in neonatal intensive care unit rates of bronchopulmonary dysplasia. J Pediatr. 2017;180:105-9.

22. Willis KA, Weems MF. Hemodynamically significant patent ductus arteriosus and the development of bronchopulmonary dysplasia. Congenit Heart Dis. 2019;14(1):27-32.

23. Woynarowska M, Rutkowska M, Szamotulska K. Risk factors, frequency and severity of bronchopulmonary dysplasia (BPD) diagnosed according to the new disease definition in preterm neonates. Med Wieku Rozwoj. 2008;12(4 Pt 1):933.

24. Dumpa V, Bhandari V, editors. Surfactant, steroids and noninvasive ventilation in the prevention of BPD. Semin Perinatol; 2018: Elsevier.

25. Cheong JL, Doyle LW, editors. An update on pulmonary and neurodevelopmental outcomes of bronchopulmonary dysplasia. Semin Perinatol; 2018: Elsevier.

26. Sahoo T, Anand P, Verma A, et al. Outcome of extremely low birth weight (ELBW) infants from a birth cohort (20132018) in a tertiary care unit in North India. J Perinatol. 2020;40(5):743-9.

27. Lemons JA, Bauer CR, Oh W, et al. Very low birth weight outcomes of the National Institute of Child health and human development neonatal research network, January 1995 through December 1996. Pediatrics. 2001;107(1):e1-e. 